Z Rheumatol

https://doi.org/10.1007/s00393-021-01066-4

๑ Der/die Autor(en) 2021

\section{Erratum zu: Zusammenhang von körperlicher Aktivität mit Fatigue und Funktionskapazität bei Patienten mit rheumatoider Arthritis}

\author{
S. Beider ${ }^{1,2} \cdot$ S. Flohr ${ }^{2} \cdot$ S. Gehlert ${ }^{2} \cdot$ T. Witte ${ }^{1} \cdot$ D. Ernst ${ }^{1}$ \\ ' Klinik für Rheumatologie und Immunologie, Medizinische Hochschule Hannover, Hannover, Deutschland \\ ${ }^{2}$ Institut für Sportwissenschaft, Universität Hildesheim, Hildesheim, Deutschland
}

Die Online-Version des Originalartikels ist unter https://doi.org/10.1007/s00393-020-00830-2 zu finden.

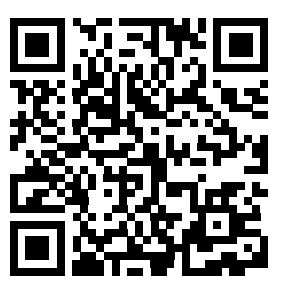

QR-Code scannen \& Beitrag online lesen

\section{Erratum zu:}

Z Rheumatol $2021 \cdot 80: 113$

https://doi.org/10.1007/s00393-020-008

30-2

Der Artikel „Zusammenhang von körperlicher Aktivität mit Fatigue und Funktionskapazität bei Patienten mit rheumatoider Arthritis" von S. Beider, S. Flohr, S. Gehlert, T. Witte und D. Ernst wurde ursprünglich Online First ohne "Open Access" auf der Internetplattform des Verlags publiziert. Nach der Veröffentlichung in Band 80, Heft 2, pp. 113-121 hatten sich die Autoren für eine "Open Access"-Veröffentlichung entschieden. Das Urheberrecht des Artikels wurde deshalb in (c) Der/die Autor(en) geändert. Dieser Artikel ist jetzt unter der Creative Commons Namensnennung 4.0 International Lizenz veröffentlicht, welche die Nutzung, Vervielfältigung, Bearbeitung, Verbreitung und Wiedergabe in jeglichem Medium und Format erlaubt, sofern Sie den/die ursprünglichen Autor(en) und die Quelle ordnungsgemäß nennen, einen Link zur Creative Commons Lizenz beifügen und angeben, ob Änderungen vorgenommen wurden.

Die in diesem Artikel enthaltenen Bilder und sonstiges Drittmaterial unterliegen ebenfalls der genannten Creative Commons Lizenz, sofern sich aus der Abbildungslegende nichts anderes ergibt. Sofern das betreffende Material nicht unter der genannten Creative Commons Lizenz steht und die betreffende Handlung nicht nach gesetzlichen Vorschriften erlaubt ist, ist für die oben aufgeführten Weiterverwendungen des Materials die Einwilligung des jeweiligen Rechteinhabers einzuholen.

Weitere Details zur Lizenz entnehmen Sie bitte der Lizenzinformation auf http://creativecommons.org/licenses/by/ 4.0/deed.de.

\section{Korrespondenzadresse}

\section{S. Beider}

Klinik für Rheumatologie und Immunologie, Medizinische Hochschule Hannover Carl-Neuberg-Str. 1, 30625 Hannover, Deutschland beider.sonja@mh-hannover.de

Open Access. Dieser Artikel wird unter der Creative Commons Namensnennung 4.0 International Lizenz veröffentlicht, welche die Nutzung, Vervielfältigung, Bearbeitung, Verbreitung und Wiedergabe in jeglichem Medium und Format erlaubt, sofern Sie den/die ursprünglichen Autor(en) und die Quelle ordnungsgemäß nennen, einen Link zur Creative Commons Lizenz beifügen und angeben, ob Änderungen vorgenommen wurden.

Die in diesem Artikel enthaltenen Bilder und sonstiges Drittmaterial unterliegen ebenfalls der genannten Creative Commons Lizenz, sofern sich aus der Abbildungslegende nichts anderes ergibt. Sofern das betreffende Material nicht unter der genannten Creative Commons Lizenz steht und die betreffende Handlung nicht nach gesetzlichen Vorschriften erlaubt ist, ist für die oben aufgeführten Weiterverwendungen des $\mathrm{Ma}$ terials die Einwilligung des jeweiligen Rechteinhabers einzuholen.

Weitere Details zur Lizenz entnehmen Sie bitte der Lizenzinformation auf http://creativecommons.org/ licenses/by/4.0/deed.de. 